\section{Heuristics and Political Elites' Judgment and Decision-Making}

DOI: $10.1177 / 14789299177503$ II journals.sagepub.com/home/psrev
Political Studies Review 2019, Vol. 17(I) 4I-52 (C) The Author(s) 2018

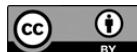

@SAGE

\title{
Barbara Vis
}

\begin{abstract}
It is broadly assumed that political elites (e.g. party leaders) regularly rely on heuristics in their judgments or decision-making. In this article, I aim to bring together and discuss the scattered literature on this topic. To address the current conceptual unclarity, I discuss two traditions on heuristics: $(\mathrm{I})$ the heuristics and biases (H\&B) tradition pioneered by Kahneman and Tversky and (2) the fast and frugal heuristics (F\&F) tradition pioneered by Gigerenzer et al. I propose to concentrate on two well-defined heuristics from the H\&B tradition-availability and representativeness - to empirically assess when political elites rely on heuristics and thereby understand better their judgments and decisions. My review of existing studies supports the notion that political elites use the availability heuristic and possibly the representativeness one for making complex decisions under uncertainty. It also reveals that besides this, we still know relatively little about when political elites use which heuristic and with what effect(s). Therefore, I end by proposing an agenda for future research.
\end{abstract}

\section{Keywords}

political decision-making, political judgment, political elites, availability heuristic, representativeness heuristic, fast and frugal heuristics, heuristics and biases

Accepted: 19 June 2017

\section{Introduction}

When taking decisions or making judgments (i.e. assessing situations that oftentimes precede decision-making; Newell et al., 2015: 20), individuals regularly apply heuristics: cognitive shortcuts or rules of thumb (see Gilovich et al., 2002). Much literature focuses on the heuristics voters use, for instance, in their information search (Bartels, 1996; Redlawsk, 2004) or preference formation (Bang Petersen, 2015). Compared to this large literature that examines empirically the heuristics voters apply, the body of work studying empirically the heuristics applied by political elites - for example, members of cabinet,

Utrecht University School of Governance, Utrecht University, Utrecht, The Netherlands

Corresponding author:

Barbara Vis, Utrecht University School of Governance, Utrecht University, Bijlhouwerstraat 6, 35 I I ZC

Utrecht, The Netherlands.

Email: b.vis@uu.nl 
party leaders, or members of parliament (MPs) - is much more scant (exceptions include Böhmelt et al., 2016; Jacobs, 2011; Kropp, 2010; Laver and Sergenti, 2012; Weyland, 2007, 2014). ${ }^{1}$ Political elites make judgments and decisions in an environment that differs from that of ordinary citizens. Elites typically have more resources and support staff, which may enable more accurate judgments and decisions (Jacobs, 2011; Weyland, 2014). Political elites' motivation to arrive at an accurate judgment may also be higher, stimulating higher effort reasoning and a more systematic mode of processing (Jacobs, 2011). Another, related difference is that ordinary citizens usually face too little information to make a "comprehensively rational" choice (Gilovich and Griffin, 2002: 3), whereas political elites regularly face too much information. A large majority $(74 \%)^{2}$ of Belgian politicians, for example, are overwhelmed by the information they receive on a daily basis (Walgrave et al. 2013: 22), making it plausible that they turn to heuristics for managing this complexity. It goes beyond this article's scope to explore the differences between ordinary citizens and elites in more detail. Still, this possible difference is one reason to concentrate on political elites' use of heuristics.

Various strands of literature on political elites' judgment or decision-making pay attention to some heuristic (e.g. Allison and Zelikov, 1999; Kingdon, 1989; Matthews and Stimson, 1975). Because these studies vary substantially in how they define the term heuristic, their findings are difficult to compare. Moreover, instead of empirically testing whether political elites rely on heuristics, such studies typically assume (for instance, because of incomplete information) that a heuristic has been employed. Establishing empirically that political elites have used a heuristic instead of simply assuming that they have is challenging (cf. Lau and Redlawsk, 2001).

Against this backdrop, my objectives are threefold. First, I address the lack of conceptual clarity by discussing two main traditions on heuristics: (1) the heuristics and biases $(H \& B)$ tradition pioneered by Kahneman and Tversky (e.g. Gilovich et al., 2002; Tversky and Kahneman, 1974) and (2) the fast and frugal heuristics (F\&F) tradition pioneered by Gigerenzer and his colleagues (e.g. Gigerenzer, 2001, 2015; Gigerenzer and Selten, 2001). While both traditions have their merits, I argue that two clearly defined, ${ }^{3}$ generalpurpose heuristics (Gilovich and Griffin, 2002: 3) from the H\&B tradition-availability and representativeness - are especially relevant to political decision-making. Knowing more about the conditions under which political elites rely on these heuristics - which underlie many others - ${ }^{4}$ will further our understanding of political judgment and decision-making. It does so because it helps to explain in the face of uncertainty which issues or proposals are likely to reach to the political agenda (through availability). And which ones are likely to be perceived as being able to solve the issue at hand (through representativeness). My second objective is to bring together and discuss a selection of studies on political elites' reliance on heuristics. Hereby, I focus mainly-but not exclusivelyon the availability and representativeness heuristics. This review shows that political elites indeed rely on these heuristics, but also that we know very little about the conditions under which a specific heuristic is used (except for the general finding that complexity and uncertainty matters). The third and final objective is therefore to bring the discussion forward by outlining an agenda for future research.

\section{What is a heuristic? Different traditions, different answers}

Heuristic is a broad term that, according to Shah and Oppenheimer (2008: 207), "has been used to describe nearly everything." In the game-theoretic literature, for example, a 
heuristic is defined as "a method or rule for solving problems" (Peyton Young, 2008: 1). And in the agent-based modeling literature as "decision-making rules of thumb that can in practice be very effective but can never be proven formally to be the best responses to any conceivable state of the world" (Laver and Sergenti, 2012: 25). Political scientists typically state that an individual employs a heuristic if she takes a decision based on anything but full information. Because more information is always possible, "nearly anything can be construed as a heuristic" (Druckman et al., 2009: 494). This not only makes what is a heuristic unclear (cf. Shah and Oppenheimer, 2008) but also impairs the accumulation of knowledge.

So, how to define heuristics? Who may be seen as the founding father of heuristics, Herbert Simon (1990: 11), defines them as "methods for arriving at satisfactory solutions with modest amounts of computation." The two traditions on heuristics mentioned above each build on Simon's definition. Let me first discuss the traditions in some more detail. The H\&B tradition emphasizes how and why using heuristics typically results in judgments or decisions that are suboptimal compared to a normative standard. This standard is oftentimes expected utility theory (Von Neumann and Morgenstern, 1944) or another variant of comprehensive rationality theory (Gilovich and Griffin, 2002). The F\&F tradition, conversely, is interested in how and why F\&F heuristics regularly allow people to make judgments or decisions that "fit" their environment and that are thereby ecologically rational (Gigerenzer, 2001; Goldstein and Gigerenzer, 2002). ${ }^{5}$ Limitations of knowledge and computational capability need not be a disadvantage. In fact, these scholars argue that if an environment is highly complex, using a heuristic may yield better decisions. Another contrast is that much research in the H\&B tradition assumes that heuristics are used automatically and largely unconsciously, per dual-process theories of mind's "system 1" reasoning (Kahneman, 2011; Kahneman and Frederick, 2002: 51-52; Stanovich and West, 2000). The F\&F tradition, conversely, generally assumes that heuristics are employed consciously (Gilovich and Griffin, 2002: 16-17), more in line with "system 2" reasoning. ${ }^{6}$

These characteristics are recognizable in the respective definitions employed. The F\&F tradition defines a heuristic as a strategy that ignores "part of the information, with the goal of making decisions more quickly, frugally, and/or accurately than more complex methods" (Gigerenzer, 2015: 112). Frugality plays no role in the H\&B tradition. Instead, the latter defines a heuristic as a substitution of an object's property with something that comes more readily to mind. A heuristic mediates judgment when people assess "a specified target attribute of a judgment object by substituting another property of that objectthe heuristic attribute - which comes more readily to mind" (Kahneman and Frederick, 2002: 53, emphases in original). Such substitution clearly takes place in the availability and the representativeness heuristics from the H\&B tradition.

People employ the availability heuristic (Tversky and Kahneman, 1973) when they assess how likely it is that something occurs (e.g. a new party entering office) by focusing on the ease with which they can think of occurrences of it (new parties that were successful in entering office). For example, in Weyland's (2014) study on the spread of political regime contention since 1848, the striking, vivid example of regime collapse in a neighboring country (availability) positively influenced citizens' willingness to protest themselves.

People use the representativeness heuristic when they assess to which degree phenomenon A (like population aging in Europe) resembles phenomenon B (population aging in the Netherlands) (Kahneman and Tversky, 1972; Tversky and Kahneman, 1974). 
Statements such as "She will win the election; you can see she is a winner" (Kahneman, 2011: 150) indicate that someone relies on representativeness, same as when someone judges "the potential leadership of a candidate for office by the shape of his chin or the forcefulness of his speeches" (Kahneman, 2011: 150). Also, politicians who think negatively about whole groups of people - for instance, Muslims - because of the activities of some of them rely on representativeness. ${ }^{7}$

\section{Political elites' reliance on heuristics and their effects}

As noted above, in many studies on political elites' judgment or decision-making, heuristics play some role. Such studies generally argue that political elites rely on a heuristic when facing too many decisions (information overload), when the information is poor, and in the presence of uncertainty (Sullivan et al., 1993: 978). These studies can be placed in the bounded rationality literature (e.g. Jones, 2001; Simon, 1955). Examples include Matthews and Stimson's (1975) study of the heuristics United States legislators employ (see also Kingdon, 1977, 1989), studies on how elites use information in foreign policymaking (e.g. Allison and Zelikov, 1999), and work building on Lindblom's (1959) notion of policy incrementalism. ${ }^{8}$ Also in the economic voting literature (Nadeau et al., 2002; Powell and Whitten, 1993; Whitten and Palmer, 1999), a decision-making shortcut is identifiable on the side of political elites. Their assumption that voters vote economically makes them try to change the economy for the better, for instance, by creating jobs or by public investments that boost economic growth, especially shortly before an election. Such behavior can give rise to political business cycles (Franzese, 2002). Except for the general statement that political elites do seem to rely on heuristics, these studies' findings are difficult to compare and accumulate given their different definitions of heuristics. Moreover, as indicated, this work typically assumes instead of showing empirically that political elites use heuristics. An exception to this last statement is Kropp (2010), who aims to demonstrate German MPs' reliance on heuristics when they scrutinize European Union (EU) policy-making. Kropp finds that MPs use a heuristic whenever they try to reduce complexity, but it remains unclear how exactly she established this. To further the discussion on political elites' use of heuristics, it makes sense to zoom in onto a selected number of well-defined yet broad heuristics that are especially useful for political judgment and decision-making. Availability and representativeness are precisely that.

\section{Do political elites employ the availability heuristic?}

Let us first assess whether political elites rely on the availability heuristic. The short answer is yes, they do. Focusing on leading policy makers in Latin America, Weyland (2007) demonstrated that the readily availability of Chile's bold and novel pension system put this model on their policy agendas. There were factors like geographic and temporal proximity - that is, availability - that influenced the policy makers' decisions, rather than a logical evaluation of which model would be best (see also Weyland, 2008). ${ }^{9}$ In his 2014-book, Weyland reconstructed the employment of the availability heuristic and the representative heuristic during three key waves of democratic contention using qualitative sources like contemporary participants' reports, diaries and eyewitness accounts. In personal communication, Weyland indicated that for operationalizing the availability heuristic, he focused mainly on disproportionate attention, references, and the subjective assignment of importance to a dramatic, vivid precedent (like the overthrow of the French King in 1848). Simultaneously, he assessed whether there were no references to other 
"objectively relevant" precedents (such as the revolutionary waves in the Italian states in the same year). Through this approach, Weyland (2014) demonstrated that political elites indeed rely on the availability heuristic. This finding is corroborated by the, to the best of my knowledge, first quantitative study on the availability (and representativeness) heuristics by Böhmelt et al. (2016). Böhmelt et al. found a significant, substantively important effect of foreign incumbents' party positions on the policy position of $>200$ domestic parties from 26 countries between 1977 and 2010. ${ }^{10}$ Importantly, their large-n set-up allowed for testing what political elites did not rely on.

While Jacobs (2011) did not employ this term himself (contrary to Weyland and Böhmelt et al.), also his study on the establishment on contributory pension schemes in Germany, Britain, the United States, and Canada supports political elites' employment of the availability heuristic. In Jacobs' account, this heuristic entered through policy makers' prior causal ideas. He showed that the options considered were shaped crucially by what was available.

\section{Do political elites employ the representativeness heuristic?}

The empirical evidence suggesting that political elites rely on the representativeness heuristic is more mixed. Supportive evidence comes, for example, from Weyland (2007), who demonstrated that leading policy makers' employment of the representativeness heuristic explains why so many countries in Latin America followed Chile's pension reform; they saw the Chilean success as representative of a larger set of reform successes (see also Weyland, 2008, 2014). In personal communication, Weyland indicated that he identified the representativeness heuristic in the qualitative material for his 2014-book (see above) by looking for emphasis on similarities with a vivid, dramatic precedent and especially through the claim "we can do this too!" Actors' assumption that such easy replicability was possible was problematic because it downplayed or neglected differences in the political situation. In fact, the latter resulted in many emulation efforts' failing. In Böhmelt et al.'s (2016) quantitative analysis, the representativeness heuristic would have been at work if the positions of foreign incumbents had influenced the positions of domestic parties of the same ideological bloc. It that case, say the domestic social democratic party would have adjusted its position to representative foreign incumbents, namely, social democratic ones. However, Böhmelt et al. (2016) did not find a significant effect for the positions of foreign incumbents of the same ideological block on a party's position and thus - contrary to Weyland's qualitative analyses - find no support for the representativeness heuristic. ${ }^{11}$

In Weyland's work, there is a relationship between the availability heuristic and the representative one, with the former shaping what is on leading policy makers' radar screen and the latter subsequently shaping how they assess this material. While such a relationship makes sense for a variety of political judgments and decisions, especially regarding institutional change, it is not a necessity. For example, the absence of a cooccurrence of the employment of these two heuristics is supported empirically by Böhmelt et al. (2016), who found support only for the availability heuristic.

\section{Under which conditions do political elites use the availability and representativeness heuristics?}

A perhaps more intriguing question is when political elites employ the availability and/or representativeness heuristic(s). Broadly speaking, individuals-including political elites - turn to heuristics when they face a high degree of uncertainty. Given that elites 
because of, for instance, their larger resources oftentimes face less uncertainty than do ordinary citizens, the former's hurdle for relying on heuristics is higher. The difference across political elites and ordinary citizens is one of degree, not of kind. Using a broader definition of elite than I adopt here (see Note 1), Hafner-Burton et al.'s (2013) review shows that elite decision makers use heuristics more effectively when processing complex information, mainly because of their larger ability to choose with automaticity. This finding supports the difference in degree not in kind notion. Also, political elites are "normal mortals" (Weyland, 2014: 58, see p. 54), who turn to heuristics at some point, namely, when the environment becomes highly uncertain and complex (see also Jacobs, 2011). This applies to many political judgments and decisions (see, for example, Bursens et al., 2017). An example is a party strategist who needs to decide on the party's policy platform; doing this "optimally" is impossible in a multidimensional setting (cf. Laver and Sergenti, 2012). Or, a government that needs to decide whether to reform the welfare state, or whether to participate in a military intervention. Such decisions are complexthere are numerous factors to consider-and how they play out is uncertain. For these types of decisions, political elites may thus rely on heuristics.

\section{What are the effects of using heuristics?}

What, then, are the effects of political elites' reliance on heuristics? In studies focusing on voters' decision-making, it is regularly assumed that heuristics defined as information shortcuts enable uninformed voters to make decisions as if they were fully informed (e.g. Lupia, 1994; Lupia and McCubbins, 1998; Lupia and Matsusaka, 2004 see Kuklinski and Quirk, 2000: 153). According to Lau and Redlawsk (2001: 952), this view on the positive effect of heuristics is so pervasive "that we could probably refer to it as the new conventional wisdom" (emphasis added). This literature tends to neglect the possible biases relating to using heuristics (exceptions include, for example, Bartels, 1996; Lau and Redlawsk, 2001). As Kuklinski and Quirk (2000: 166) note, by "viewing heuristics as rational strategies for dealing with ignorance, political scientists have stressed how they enhance competence"- in line with the F\&F tradition. What they did not do is "looked for problems with them" (Kuklinski and Quirk, 2000: 166).

The heuristics and biases tradition, conversely, has focused explicitly on biases in the sense of deviations from comprehensive rationality. ${ }^{12}$ Reliance of the availability heuristic biases attention in confirmatory ways (Jacobs, 2011: 249, see Lau et al., 1991: 671-672). This is because of individuals' "tendency to seek out and remember dramatic cases or because the broader world's tendency to call attention to examples of a particular (restricted) type" (Gilovich and Griffin: 3). The media can function as a magnifier here, because of its focus on what is newsworthy. The latter typically are vivid or dramatic events. What is focused on may then not reflect voters' preferences (Miler, 2009). If attention bias results in some groups' voices not being considered, because they do not or cannot bring across their wishes vividly, this poses problems for democratic representation.

A bias that is associated with the representativeness heuristic that is particularly relevant for political judgment and decision-making is base rate neglect, that is, failing to consider how likely a phenomenon's occurrence in general is. Concretely, this leads to drawing "excessively firm conclusions from small samples [...]" (Weyland, 2014: 8), basing conclusions on (too) short time frames, or overlooking the role of chance (see Weyland, 2008). Hereby, also relying on the representativeness heuristic may pose problems for democratic representation. 
Interestingly, using heuristics poses no problem for democratic representation in the F\&F perspective. If using a heuristic may trump a more elaborate strategy (see Goldstein et al., 2001, for a discussion of when and why simple (F\&F) heuristics work), elites relying on heuristics may be good news for democracy. If, for example, an American President is an expert in foreign policy decisions, the first thing that comes to his mind-per F\&F take-the-first heuristic - probably produces a good decision. But this will be the case only if this President is truly an expert in this area, since experience does not by itself leads to superior (decision-making) performance (Ericsson and Lehmann, 1996: 276).

\section{Where to go from here?}

For understanding better political elites' judgments and decision-making, it is important to know more of the heuristics they rely on. While the term regularly appeared in existing literature, the conceptual unclarity about what is a heuristic (i.e. how to define the term) impaired the accumulation of knowledge. Moreover, most extant studies assumed that political elites used heuristics instead of demonstrating this empirically. To further the debate, it is important to have conceptual clarity about what is a heuristic, establish what is our current knowledge on political elites' reliance on heuristics, and indicate where we should go from there.

I discussed two main traditions to heuristics-H\&B tradition of Kahneman and Tversky and F\&F tradition of Gigerenzer and colleagues - both of which are identifiable in political science research. I proposed that the H\&B tradition's definition of heuristic as a substitution of an object's property of something that comes more readily to mind is most appropriate for examining political elites' judgments and decision-making. Therefore, I zoomed in onto two H\&B tradition: availability and representativeness. Given the small-n nature of most existing studies (e.g. Jacobs, 2011; Weyland, 2008, 2014), it was unclear whether the results would travel to a larger set of cases. This made Böhmelt et al.'s (2016) study so relevant, because it provided the first large-n evidence that they do, at least for availability. When having to make complex judgments and decisions with uncertain outcomes, political elites rely on heuristics. What the extant studies did not offer - and which they admittedly were not aiming to offer-was a measure of political elites' employment of the availability and/or representativeness heuristics. To understand better under which conditions which political elites use which heuristic and with what effect, such a measure would be extremely valuable. This measure would help to answer a range of novel, substantive research questions. For example, does the reliance on heuristics vary across types of political elites or by ideology? To what extent does the media or the Internet influence political elites' reliance on heuristics, and has this changed over time?

The increasing availability of relevant data and possibilities for analyzing such data allows for developing large-n applications to answer these and related questions. Text data would be a useful starting point for such large-n analyses. There are at least two options for using these data: (1) to create a measure of heuristics' use by individual political actors (e.g. a party leader or MP) and (2) to assess whether the behavior of, for instance, political parties or governments indicates that they employ heuristics. For option 1, potentially relevant text data include cabinet members' tweets, parliamentary debates (Proksch and Slapin, 2015), and or party leader speeches (Schumacher et al., 2016). To arrive at a measure of an actor's use of the representativeness heuristic, for example, the text data can be analyzed with (computer-assisted) text analysis tools to identify actor's references to 
something that signals a "we can do this too!" claim (such as a reference to success of a sister party abroad or of a rival domestic party). For option 2, possibly relevant text data include party manifestos (Manifesto Research on Political Representation project; Volkens, 2015), data on policy agendas collected by the Comparative Agendas Project (e.g. Alexandrova et al., 2014, for the EU's policy agenda; John et al., 2013, for the UK's agenda), and press releases (Klüver and Sagarzazu, 2015, 2016; Van der Velden et al., 2017). Topic modeling, an automated method to identify topics in texts (Grimmer, 2010; Grimmer and Stewart, 2013), can be used to identify the topics the political actors focus on and hereby helps to establish whether they relied on heuristics. To arrive at a measure of availability, for example, researchers need to establish that actors pay disproportionate attention to a typically vivid or dramatic precedent or factor while simultaneously ignoring (an)other-also, and perhaps even more, relevant - factor(s). Although they do not discuss this themselves, two recent studies suggest that political parties use the availability heuristic when drafting their party manifestos, ${ }^{13}$ with the state of the economy serving as what is available - the "vivid" precedent (Greene, 2016; Williams et al., 2016). ${ }^{14}$

Text analysis allows for creating an indirect measure of political elites' employment of heuristics. An underlying assumption here is that what political elites say reflects their thinking - an assumption that may be wrong. Moreover, politics is subject to a process of rationalization (Meyer et al., 1997). Text analysis should therefore ideally be complemented by an approach that assesses elites' thinking more directly: experiments with political elites as participants (cf. Fatas et al., 2007; Linde and Vis, 2017). Getting a sample of elites to run an experiment that has enough power is challenging, especially for the most powerful elites. However, if such a sample can be obtained, the benefits are very large. One route to conduct elite experiments is to use seminal, well-known, so-called problems from the ample existing experiments on heuristics (see Gilovich et al., 2002, for an overview). Another route is to conduct a conjoint experiment (Hainmueller et al., 2014). In the latter case, existing findings on the factors invoking the employment of a specific heuristic (such as vivid information invoking the availability heuristic) are the starting point. These factors, including their absence, are then varied randomly and their causal effect estimated by means of the conjoint analysis. The advantage of the latter is that it allows for testing experimentally under which conditions political elites employ which heuristic. ${ }^{15}$ Each of these routes could also be included in an elite survey. These methodological ways forward can augment our understanding of political elites' reliance on heuristics and thereby help to understand better political elites' judgment and decision-making.

\section{Acknowledgements}

A previous version of this article has been presented at the Political Psychology Conference Amsterdam, the Netherlands, in 2015, and has benefited to the participants' comments and suggestions. In addition, I thank Kurt Weyland for his permission to make use of our personal communication on how he identified heuristics in his 2014-book. Also, many thanks to Political Studies Review three anonymous reviewers' extensive and detailed comments. The research reported in this article was carried out at the Vrije Universiteit Amsterdam.

\section{Funding}

The author(s) disclosed receipt of the following financial support for the research, authorship, and/or publication of this article: B.V.'s work is funded by a VIDI grant from the Netherlands Organization for Scientific Research (NWO, grant no. 452-11-005). 


\section{ORCID iD}

Barbara Vis (iD https://orcid.org/0000-0003-2323-3862

\section{Notes}

1. Hafner-Burton et al. (2013) could be another example, but their definition of elite is broader than the one I adopt here.

2. Of the 85 Dutch-speaking members of the Belgian federal parliament, (junior) ministers, and party chairpersons.

3. Scholars from the fast and frugal heuristics $(\mathrm{F} \& \mathrm{~F})$ tradition probably disagree with this statement (cf. Kelman, 2011: 85).

4. For instance, the representativeness heuristic subsumes the coalition-based heuristics (Adams et al., 2016; Fortunato and Stevenson, 2013) and the party heuristic (see Lau and Redlawsk, 2001) that voters apply.

5. This characteristic relates to the approach to heuristics in the game-theoretic and agent-based literatures.

6. Also some heuristics and biases $(\mathrm{H} \& \mathrm{~B})$ researchers argue that heuristics can be employed consciously (see Gilovich and Griffin, 2002: 5).

7. This can be both a decision-making shortcut and a consciously invoked strategy to appeal to some voters; the crux is how to establish which one it is.

8. The latter strand of work typically studies bureaucrats instead of political elites.

9. Chile's bold pension reform was probably an inappropriate model to follow for many Latin American counties (Weyland, 2007).

10. Böhmelt et al. (2016) do not discuss their finding using this term.

11. Böhmelt et al. do not discuss their finding as evidence against the representativeness heuristic.

12. The existence of biases does not mean that applying the availability or representativeness heuristic is irrational per se. As estimation procedures, heuristics are sensible (Gilovich and Griffin, 2002). Moreover, as stressed by F\&F scholars, while the employment of a heuristic deviates from comprehensive rationality, it can still be ecologically rational. Whether applying a specific heuristic in a specific context is irrational, and from which perspective, is an empirical question that is beyond the scope of this article.

13. Thanks to an anonymous reviewer for pointing this out.

14. Note that whereas Greene (2016) finds that when the economy grows, parties increase the attention to their economic competence, Williams et al. (2016) find that governing parties pay more attention to the economy in bad economic times (worsening unemployment and inflation; economic growth has a nonsignificant, negative, effect).

15. Both routes could be followed, yet not on the same data.

\section{References}

Adams J, Ezrow L and Wlezien C (2016) The Company You Keep: How Voters Infer Party Positions on European Integration from Governing Coalition Arrangements. American Journal of Political Science 60 (4): 811-823.

Alexandrova P, Carammia M, Princen S, et al. (2014) Measuring the European Council Agenda: Introducing a New Approach and Dataset. European Union Politics 15 (1): 152-167.

Allison G and Zelikov P (1999) Essence of Decision: Explaining the Cuban Missile Crisis, 2nd edn. New York: Addison Wesley Longman.

Bang Petersen M (2015) Evolutionary Political Psychology: On the Origin and Structure of Heuristics and Biases in Politics. Advances in Political Psychology 36 (1): 45-78.

Bartels LM (1996) Uninformed Votes: Information Effects in Presidential Elections. American Journal of Political Science 40 (1): 194-230.

Böhmelt T, Ezrow L, Lehrer R, et al. (2016) Party Policy Diffusion. American Political Science Review 110 (2): $1-14$.

Bursens P, Landtsheer CD, Braekmans L, et al. (2017) Complex Political Decision-Making: Leadership, Legitimcacy and Communication. London: Routledge.

Druckman JN, Kuklinski JH and Sigelman L (2009) The Unmet Potential of Interdisciplinary Research: Political Psychological Approaches to Voting and Public Opinion. Political Behavior 31 (4): 485-510.

Ericsson KA and Lehmann AC. (1996) Expert and Exceptional Performance: Evidence of Maximal Adaptation to Task Constraints. Annual Review Psychology 47: 273-305. 
Fatas E, Neugebauer T and Tamborero P (2007) How Politicians Make Decisions: A Political Choice Experiment. Journal of Economics 92 (2): 167-196.

Fortunato D and Stevenson RT (2013) Perceptions of Partisan Ideologies: The Effect of Coalition Participation. American Journal of Political Science 57 (2): 459-477.

Franzese RJ Jr. (2002) Electoral and Partisan Cycles in Economic Policies and Outcomes. Annual Review of Political Science 5: 369-421.

Gigerenzer G (2001) The Adaptive Toolbox. In: Selten R and Gigerenzer G (eds) Bounded Rationality: The Adaptive Toolbox. Cambridge, MA; London: The MIT Press, pp.37-50.

Gigerenzer G (2015) Simply Rational: Decision Making in the Real World. Oxford: Oxford University Press.

Gigerenzer G and Selten R (2001) Rethinking Rationality. In: Selten R and Gigerenzer G (eds) Bounded Rationality: The Adaptive Toolbox. Cambridge, MA; London: The MIT Press, pp.1-12.

Gilovich T and Griffin D (2002) Introduction Heuristics and Biases: Then and Now. In: Gilovich T, Griffin D and Kahneman D (eds) Heuristics and Biases: The Psychology of Intuitive Judgment. New York: Cambridge University Press, pp.1-18.

Gilovich T, Griffin D and Kahneman D (eds) (2002) Heuristics and Biases: The Psychology of Intuitive Judgment. New York: Cambridge University Press.

Goldstein D and Gigerenzer G (2002) Models of Ecological Rationality: The Recognition Heuristic. Psychological Review 109 (1): 75-90.

Goldstein DG, Hogarth RM, Kacelnik A, et al. (2001) Group Report: Why and When Do Simple Heuristics Work? In: Selten R and Gigerenzer G (eds) Bounded Rationality: The Adaptive Toolbox. Cambridge, MA; London: The MIT Press, pp.173-190.

Greene Z (2016) Competing on the Issues: How Experience in Government and Economic Conditions Influence the Scope of Parties' Policy Messages. Party Politics 22 (6): 809-822.

Grimmer J (2010) A Bayesian Hierarchical Topic Model for Political Texts : Measuring Expressed Agendas in Senate Press Releases. Political Analysis 18 (1): 1-35.

Grimmer J and Stewart BM (2013) Text as Data: The Promise and Pitfalls of Automatic Content Analysis Methods for Political Texts. Political Analysis 21 (3): 267-297.

Hafner-Burton E, Hughes A and Victor D (2013) The Cognitive Revolution and the Political Psychology of Elite Decision Making. Perspectives on Politics 11 (2): 368-386.

Hainmueller J, Hopkins DJ and Yamamoto T (2014) Causal Inference in Conjoint Analysis: Understanding Multidimensional Choices via Stated Preference Experiments. Political Analysis 22 (1): 1-30.

Jacobs AM (2011) Governing for the Long Term: Democracy and the Politics of Investment. New York: Cambridge University Press.

John P, Bertelli A, Jennings W, et al. (2013) Policy Agendas in British Politics. Basingstoke: Palgrave Macmillian.

Jones BD (2001) Politics and the Architecture of Choice: Bounded Rationality and Governance. Chicago, IL; London: The University of Chicago Press.

Kahneman D (2011) Thinking, Fast and Slow. London: Penguin Books.

Kahneman D and Frederick S (2002) Representativeness Revisited: Attribute Substitution in Intuitive Judgment. In: Gilovich T, Griffin D and Kahneman D (eds) Heuristics and Biases: The Psychology of Intuitive Judgment. New York: Cambridge University Press, pp.49-81.

Kahneman D and Tversky A (1972) Subjective Probability: A Judgment of Representativeness. Cognitive Psychology 3 (3): 430-454.

Kelman M (2011) The Heuristics Debate. Oxford: Oxford University Press.

Kingdon JW (1977) Models of Legislative Voting. The Journal of Politics 39 (3): 563-595.

Kingdon JW (1989) Congressmen's Voting Decisions, 3rd edn. Ann Harbor, MI: The University of Michigan Press.

Klüver H and Sagarzazu I (2015) Coalition Governments and Party Competition: Political Communication Strategies of Coalition Parties. Political Science Research and Methods 5: 333-349.

Klüver H and Sagarzazu I (2016) Setting the Agenda or Responding to Voters? Political Parties, Voters and Issue Attention. West European Politics 39 (2): 380-398.

Kropp S (2010) German Parliamentary Party Groups in Europeanised Policymaking: Awakening from the Sleep? Institutions and Heuristics as MPs' Resources. German Politics 19 (2): 123-147.

Kuklinski JH and Quirk PJ (2000) Reconsidering the Rational Public: Cognition, Heuristics, and Mass Opinion. In: Lupia A, McCubbins MD and Popkin SL. (eds) Elements of Reason: Cognition, Choice, and the Bounds of Rationality. Cambridge: Cambridge University Press, pp.153-182.

Lau RR and Redlawsk DP (2001) Advantages and Disadvantages of Cognitive Heuristics in Political Decision Making. American Journal of Political Science 45 (4): 951-971. 
Lau RR, Smith RA and Fiske ST (1991) Political Beliefs, Policy Interpretations, and Political Persuasion. The Journal of Politics 53 (3): 644-675.

Laver M and Sergenti E (2012) Party Competition: An Agent-Based Model. Princeton, NJ: Princeton University Press.

Lindblom CE (1959) The Science of “Muddling Through.” Public Administration Review 19(2): 79-88.

Linde J and Vis B (2017) Do Politicians Take Risks Like the Rest of Us? An Experimental Test of Prospect Theory Under MPs. Political Psychology 38 (1): 101-117.

Lupia A (1994) Shortcuts Versus Encyclopedias: Information and Voting Behavior in California Insurance Reform Elections. American Political Science Review 88(1): 63-76.

Lupia A and McCubbins MD (1998) The Democratic Dilemma: Can Citizens Learn What They Need to Know? Cambridge: Cambridge University Press.

Lupia A and Matsusaka JG (2004) Direct Democracy: New Approaches to Old Questions. American Review of Political Science 7: 463-482.

Matthews DR and Stimson J (1975) Yeas and Nays: Normal Decision-making in the U.S. House of Representatives. New York: Wiley Inter-science.

Meyer JW, Boli J, Thomas GM, et al. (1997) World Society and the Nation State. American Journal of Sociology 103 (1): 144-181.

Miler K (2009) The Limitations of Heuristics for Political Elites. Political Psychology 30(6): 863-894.

Nadeau R, Niemi RG and Yoshinaka A (2002) A Cross-National Analysis of Economic Voting: Taking Account of the Political Context across Time and Nations. Electoral Studies 21 (3): 403-423.

Newell BR, Lagnado DA and Shanks DR (2015) Straight Choices: The Psychology of Decision Making, 2nd edn. Hove and New York: Psychology Press.

Peyton Young H (2008) Learning and Evolution in Games: Adaptive Heuristics. In: Durlauf SN and Blume LE (eds) New Palgrave Dictionary of Economics. The New Palgrave Dictionary of Economics Online: Palgrave Macmillan.

Powell GB and Whitten GD (1993) A Cross-National Analysis of Economic Voting: Taking Account of the Political Context. American Journal of Political Science 37(2): 391-414.

Proksch S-O and Slapin JB (2015) The Politics of Parliamentary Debate: Parties, Rebels, and Representation. Cambridge: Cambridge University Press.

Redlawsk DP (2004) What Voters Do: Information Search During Election Campaigns. Political Psychology 25 (4): 595-610.

Schumacher G, Schoonvelde M, Dahiya T, et al. (2016) EU Speech. A Dataset of EU Elite Speeches 20072015. Version 2.0.

Shah AK and Oppenheimer DM (2008) Heuristics Made Easy: An Effort-Reduction Framework. Psychological Bulletin 134 (2): 207-222.

Simon HA (1955.) A Behavioral Model of Rational Choice. Quarterly Journal of Economics 69 (1): 99-118.

Simon HA (1990) Invariants of Human Behavior. Annual Review of Psychology 41: 1-19.

Stanovich KE and West RF (2000) Individual Differences in Reasoning: Implications for the Rationality Debate? Behavioral and Brain Sciences 23: 645-726.

Sullivan JL, Shaw LE, McAvoy GE, et al. (1993) The Dimensions of Cue-Taking in the House of Representatives: Variation by Issue Area. The Journal of Politics 55 (4): 975-997.

Tversky A and Kahneman D (1973) Availability: A Heuristic for Judging Frequency and Probability. Cognitive Psychology 5 (2): 207-232.

Tversky A and Kahneman D (1974) Judgment Under Uncertainty: Heuristics and Biases. Science 185(4157): 1124-1131.

Van der Velden M, Schumacher G and Vis B (2017) Living in the Past or Living in the Future? Analyzing Parties' Platform Change In-between Elections, The Netherlands 1997-2014. Political Communication. DOI: $10.1080 / 10584609.2017 .1384771$.

Volkens A (2015) The Manifesto Data Collection. Manifesto Project (MRG/CMP/MARPOR) (Version 2015a). Berlin: Wissenschaftszentrum Berlin Für Sozialforschung (WZB).

Von Neumann J. and Morgenstern O (1944) Theory of Games and Economic Behavior. Princeton, NJ: Princeton University Press.

Walgrave S, Epping L, Sevenans J, et al. (2013) Het Informatiemenu Van Politici En Hun Medewerkers: Resultaten Van Interviews Met Federale Parlementsleden, Ministers, Partijvoorzitters En Hun Persoonlijke Medewerkers. Antwerp: University of Antwerp.

Weyland K (2007) Bounded Rationality and Policy Diffusion: Social Sector Reform in Latin America. Princeton, NJ; Oxford: Princeton University Press. 
Weyland K (2008) Towards a New Theory of Institutional Change. World Politics 60 (2): 281-314.

Weyland K (2014) Making Waves: Democratic Contention in Europe and Latin America since the Revolutions of 1848. New York: Cambridge University Press.

Whitten GD and Palmer HD (1999) Cross-National Analyses of Economic Voting. Electoral Studies 18(1): 49-67.

Williams LK, Seki K and Whitten GD (2016) You've Got Some Explaining to Do: The Influence of Economic Conditions and Spatial Competition on Party Strategy. Political Science Research and Methods 4(1): 47-63.

\section{Author Biography}

Barbara Vis is Professor of Politics \& Governance at the Utrecht University School of Governance. Her work on, for instance, the politics of welfare state reform and the behavior of political parties, has been published in journals such as American Journal of Political Science and European Journal of Political Research. Her most recent monograph is Comparative Welfare State Politics (2014, Cambridge UP, with Kees van Kersbergen). 